\title{
PARA ALÉM DO RELATÓRIO: REFLEXÕES SOBRE A REALIZAÇÃO DE UM EVENTO COMO A V REA-XIV ABANNE ${ }^{1}$
}

\author{
Nádia Meinerz ${ }^{2}$ \\ Claudia Mura ${ }^{3}$ \\ Jordânia de Araújo Souza ${ }^{4}$
}

\begin{abstract}
RESUMO
A publicação do presente texto objetiva compartilhar com um público mais amplo os desafios que foram enfrentados e as estratégias acionadas na organização da V Reunião Equatorial de Antropologia (REA) e XIV Reunião de Antropólogos do Norte e Nordeste (ABANNE) ocorrida no ano de 2015, em Maceió. Nosso intuito ao divulgar os resultados dessa experiência é viabilizar uma maior aproximação com os desafios e os potenciais que esses eventos apresentam, bem como a abertura de um espaço de diálogo em torno de tais questões, de modo a colaborar com a organização dos futuros congressos.
\end{abstract}

\author{
PALAVRAS-ChAVE: \\ REA; ABANNE; Antropologia; Desafios; Contribuições
}

\section{BEYOND THE REPORT: REFLECTIONS ON THE CONSTRUCTION OF AN EVENTSUCH AS THEV REA - XIV ABANNE}

\begin{abstract}
The publication of this text aims to share with a broader audience the challenges that were faced and the strategies involved in the organization of the Fifth Equatorial Meeting of Anthropology (REA) and XIV Meeting of North and Northeast Anthropologists (ABANNE) in the year 2015, in Maceió. Our aim in disseminating the results of this experience is to enable a greater approximation with the challenges and potential that these events present, as well as the opening of a space for dialogue around such issues, in order to collaborate with the organization of future congresses.
\end{abstract}

\section{KEY-WORDS}

REA; ABANNE; Anthropology; Chalenges; Contributions

\begin{abstract}
${ }^{1}$ Agradecemos ao professor Siloé Soares de Amorim, coordenador da V REA-XIV ABANNE pela dedicação incondicional à organização do evento, e que segue respondendo pelas diversas demandas e desdobramentos de cada uma das atividades. A sistematização dessas reflexões só foi possível mediante a liberação das autoras das inúmeras atribuições burocráticas, administrativas e financeiras.
\end{abstract}

${ }^{2}$ Professora do Programa de Pós-Graduação em Antropologia Social - Universidade Federal de Alagoas.

${ }^{3}$ Professora do Programa de Pós-Graduação em Antropologia Social - Universidade Federal de Alagoas.

${ }^{4}$ Professora da Universidade Federal de Alagoas; doutoranda do Programa de Pós-Graduação em Antropologia da Universidade Federal de Pernambuco. 


\title{
MÁS ALLÁ DE LA RELATORÍA: REFLEXIONES SOBRE LA REALIZACIÓN DE UN EVENTO COMO LA VREA - XIVABANNE
}

\section{RESUMEN}

La publicación de este documento tiene como objetivo compartir con un público más amplio los desafíos que se enfrentaron y las estrategias impulsadas durante la organización de la V Reunión de Antropología Ecuatorial (REA) y XIV Reunión de antropólogos del Norte y Nordeste (ABANNE), evento realizado en Maceió en el año 2015. La divulgación del proceso de construcción y de los resultados alcanzados en esta experiencia tiene también la intención de permitir una mayor aproximación a los problemas y a las posibilidades que proporcionan estos eventos, así como abrir un espacio para el diálogo y colaborar con la organización de futuros congresos.

\section{PALABRAS-CLAVE}

REA; ABANNE; Antropología; Desafíos; Contribuciones

\section{AU-DELÀ DU RAPPORT: RÉFLEXIONSSUR LA RÉALISATION D'UNÉVÉNEMENT COMME LA VREA-XIVABANNE}

\begin{abstract}
RÉSUMÉ
La publication de ce document vise à partager avec un plus large public les défis qui ont été confrontés et des stratégies axées sur l'organisation de la V Réunion Équatoriale d'Anthropologie (REA) et XIV Réunion des Anthropologues du Nord et du Nord-Est (ABANNE) au cours de l'année 2015, à Maceió. Notre intention de diffuser les résultats de cette expérience est de permettre un regard plus proche des défis et du potentiel que ces événements ont, ainsi que l'ouverture d'un espace de dialogue autour de ces questions. Il s'agit d'une initiative, afin de collaborer avec l'organisation de congrès et évènements futurs.
\end{abstract}

\section{MOTS-CLÉS}

REA; ABANNE; Anthropologie; Défis; Contributions 


\section{APRESENTAÇÃO}

O texto que aqui se apresenta é uma versão do relatório científico enviado às agências financiadoras CAPES (Coordenação de Aperfeiçoamento de Pessoal de Nível Superior) e FAPEAL (Fundação de Amparo à Pesquisa do Estado de Alagoas), com acréscimos de informações sobre a experiência de organização e realização da V Reunião Equatorial de Antropologia (REA) e XIV Reunião de Antropólogos do Norte e Nordeste (ABANNE) em Maceió, em 2015.

A divulgação deste texto objetiva socializar os desafios enfrentados e as estratégias acionadas para alcançar os resultados almejados, com o intuito de cooperar para o debate acerca dos impactos e contribuições do evento nas instituições envolvidas em nível local, regional e nacional. Visa também incentivar uma mais ampla divulgação dos resultados dessas experiências, no intuito de viabilizar uma aproximação maior aos desafios e potencialidades que esses eventos apresentam, bem como às escolhas realizadas e às controvérsias instauradas. Nesse sentido, consideramos que tornar públicas as especificidades dos contextos vivenciados pelas instituições que optam por sediar eventos e as diversas ações e questões envolvidas na sua realização, possam abrir espaço para uma maior interlocução entre tais instituições e uma profícua colaboração na organização dos futuros congressos.

\section{ORGANIZAÇÃO E REALIZAÇÃO dO EVENTO: DESAFIOS E ALCANCES}

A realização da V REA e XIV ABANNE na cidade de Maceió, no estado de Alagoas, alcançou significativos e múltiplos propósitos almejados pela Comissão Organizadora, bem como outros que vieram a se somar no decorrer desta experiência. Nessa edição, cujo tema é partilhado pela Revista Mundaú em sua primeira edição, foram enfatizados os "Direitos diferenciados, conflitos e produção de conhecimentos".

Os congressos, realizados de 19 a 22 de julho de 2015, oportunizaram pôr em pauta as reflexões e pesquisas que vêm sendo desenvolvidas no âmbito da Antropologia, não apenas em nível local, mas também regional, nacional e em alguma medida também internacional. Eles favoreceram a divulgação dos estudos antropológicos produzidos tanto pelos profissionais que fazem parte do corpo docente e discente de Instituições de Ensino Superior quanto por pesquisadores/profissionais que se encontram atuando em outros órgãos em interface com a antropologia, a exemplo do Ministério Público Federal, da Fundação Nacional do Índio, do Instituto Nacional de Colonização e Reforma Agrária, da Secretaria Nacional de Promoção dos Direitos da Pessoa com Deficiência, de ONGs, dentre 
outros. Neste sentido, é possível afirmar que a realização dos congressos permitiu uma maior visibilidade das produções antropológicas e de suas possibilidades de contribuição para a reflexão/atuação em diferentes contextos, especialmente no estado de Alagoas que, pela primeira vez, sediou o evento.

A efetivação de uma parceria público-privada para realização do evento no estado de Alagoas merece destaque como resultado importante. Acreditamos que, por meio da colaboração entre a Universidade Federal de Alagoas e o Centro Universitário Tiradentes foi possível garantir aos congressistas uma ótima infraestrutura a um custo relativamente baixo. De um lado, o suporte logístico do Centro Universitário Tiradentes permitiu a concentração das atividades em um único local, bem localizado em relação à rede hoteleira da cidade, com a disponibilidade privilegiada de recursos de climatização, projeção, acesso à internet e a serviços de impressão, além de boas ofertas de alimentação e transporte. Ao mesmo tempo, a organização lançou mão de uma série de estratégias públicas para a mobilização de recursos, tais como: a dedicação de professores e alunos da Ufal em toda a organização do evento; o custeio do material de divulgação e de grande parte do deslocamento dos professores convidados; a disponibilização de alojamento; o domínio para instalação do site com os anais dos eventos, entre outros. As trocas mobilizadas por essa parceria possibilitaram a construção de um evento de caráter público, aberto a toda a comunidade, num espaço de ensino tradicionalmente privado.

Como já referido, a V REA/XIV ABANNE contou com uma participação significativa de profissionais de diferentes instâncias e instituições em nível municipal, estadual e federal, cuja atuação está voltada à garantia dos direitos constitucionais de coletividades desfavorecidas. Tais profissionais estabeleceram e consolidaram redes de interlocução com os professores e pesquisadores que gerenciaram as múltiplas atividades nos congressos, com destaque para os Fóruns e as Sessões Extramuros. Nessa tipologia de atividades houve também uma participação importante de lideranças indígenas, quilombolas e de diversos grupos religiosos que expressaram reivindicações e pleitos em relação ao estado de Alagoas. Acreditamos que essa participação foi um importante resultado dos congressos que, além de abrir espaço para a manifestação das demandas sociais, tem proporcionado a construção do diálogo entre pesquisadores, professores, profissionais de diversos órgãos e membros das mencionadas coletividades visando o refinamento da compreensão das dinâmicas socioculturais e políticas locais.

Construir essa participação, no entanto, também suscita uma série de desafios, seja em termos logísticos e organizacionais quanto no que se refere à dinâmica da discussão acadêmica. Dois momentos durante a preparação do evento nos ajudam a ilustrar as tensões envolvidas nessa empreitada. A definição do material a ser fornecido aos congressistas foi 
ponto de pauta em várias das reuniões realizadas na sede da MEP - Eventos. Foi relativamente consensual a disponibilização de um material enxuto que contasse apenas com a programação completa, com título dos trabalhos elou dos autores. Usaríamos apenas o detalhamento das atividades ao invés de um volume completo com os resumos de todas as exposições e comunicações. Era fundamental reduzir custos! Muitas divergências surgiram, entretanto diante do suporte físico para esse material. Os custos de usar uma pasta de lona/tecido e de um encarte simples de papel foram comparados. Dentre as diferentes ideias, uma voz atrevida defendeu que aproveitássemos a ocasião para colaborar com as quilombolas da Serra das Viúvas de Água Branca ${ }^{5}$ e sua cooperativa de artigos em palha de coco. O debate estava instaurado.

De um lado a racionalidade econômica e as dificuldades de financiamento eram destacadas. De outro, o compromisso político da universidade com essas comunidades e a originalidade que as bolsas da Serra das Viúvas iam conferir ao evento apareciam como argumentos também legítimos. Não houve consenso e a definição foi feita a partir de uma votação entre os presentes. Outras dificuldades de climáticas, de transporte, de armazenamento do prazo e do adiantamento em espécie do qual a comunidade precisava para iniciar os trabalhos foram contornadas com a ajuda de todos (mesmo dos que inicialmente se mostravam resistentes à ideia) em prol dessa decisão coletiva.

Outro impasse ilustra ainda melhor o deslocamento que presença desse tipo de participante não convencional provoca na lógica das reuniões científicas. A participação de lideranças indígenas em algumas atividades do congresso trouxe além de muito trabalho de mobilização do grupo e na captação de recurso para subsidiar o seu deslocamento do interior para a capital, também provocou uma tensão entre os professores das diferentes instituições envolvidos na organização. Poucas semanas antes do evento, numa reunião geral realizada no UNIT foi pautado um conjunto de normas relativas à ocupação do espaço institucional. Várias adaptações logísticas foram rapidamente acordadas enquanto que algumas regras aparentemente banais provocaram calafrios entre os antropólogos que pesquisam entre grupos indígenas, quilombolas e movimentos sociais: Entre as expectativas de boa convivência há um apego especial a interdições como "sentar no chão", "pisar na grama" e outras relativas à "circulação de crianças".

Várias ponderações foram feitas sobre o significado que uma advertência dos seguranças da instituição, frente a comportamentos que lidos como inadequados, poderia assumir para esses sujeitos. Ao mesmo tempo, começaram a se tornar explícitos os limites de

\footnotetext{
${ }^{5}$ Além das bolsas produzidas pelas "Viúvas de Água Branca", o evento pode receber também a produção de um filme dirigido por Siloé Soares de Amorim, com roteiro de Siloé Amorim e Pedro Simonard(UNIT). Esse vídeo mostra a produção das bolsas pela Associação das Mulheres Artesãs Quilombolas da Serra das Viúvas. Para assistí-lo acesse: https://www.youtube.com/watch?v=vi8THrmosgU
} 
agência dos professores e de mobilização da estrutura funcional na sede do evento, bem como as contradições entre a lógica da universidade pública e dos centros privados de ensino. O caráter sensível que essa problemática assume entre os antropólogos, a proximidade do evento e o acúmulo de atividades profissionais ${ }^{6}$ também contribuiu para uma exaltação dos ânimos entre os professores das duas instituições. É interessante notar como, em certo momento, a preocupação com um possível conflito começou a se confundir com uma série de dúvidas em relação aos objetivos e o significado do próprio evento para cada um dos integrantes da comissão organizadora. Dessas duas situações, gostaríamos de enfatizar a complexidade das condições de diálogo e das trocas estabelecidas durante a construção do evento e o fomento a partir dele, de ações comprometidas com a defesa dos direitos e conhecimentos diferenciados.

Em relação à mobilização das redes de contato e parcerias internacionais, houve uma participação limitada de profissionais oriundos de instituições de outros países nas atividades dos congressos. Entre as razões destaca-se as dificuldades orçamentárias dos congressos, as quais inviabilizaram a oferta de incentivos para atração e até mesmo algum suporte ou auxílio para aqueles profissionais de fora do país, diretamente envolvidos em atividades como mesas redondas, grupos de trabalho e Mostra Audiovisual.

No entanto, é preciso destacar que, apesar das dificuldades mencionadas, os congressos viabilizaram a constituição de uma rede de interlocução e cooperação para além das fronteiras do país. Com efeito, contou com a participação de quatro conferencistas oriundos de México, Colômbia e Canadá que contribuíram sensivelmente para as discussões sobre o tema proposto pelo evento - direitos diferenciados, conflitos e produção de conhecimentos. A vinda desses profissionais foi integralmente custeada pela Universidade Federal de Alagoas, comprometida com a efetiva contribuição dos congressos para a internacionalização do campo da Antropologia Brasileira. Além dos conferencistas financiados pela Ufal, contamos também com a participação de mais dois profissionais do exterior que vieram com recursos próprios, o que demostra um esforço dirigido à consolidação das redes de interlocução precedentemente estabelecidas, viabilizando, assim, a continuação e o aprofundamento do diálogo sobre temáticas de interesse comum aos profissionais que atuam nas instituições brasileiras.

\footnotetext{
${ }^{6}$ No UNIT o momento era de uma série de mudanças administrativas relativas à mudança de status da instituição (Faculdade para Centro Universitário), além de todos os preparativos para o início do semestre letivo. Na UFAL, apesar da greve docente e técnica, os professores estavam em pleno processo seletivo da primeira turma do Mestrado em Antropologia.
} 
No que diz respeito a acessibilidade, a V REA/XIV ABANNE pode dispobinibilizar a programação do evento em braile ${ }^{7}$ e teve suas conferências simultaneamente traduzidas para língua de sinais. A experiência de organização da $V$ REA/XIV ABANNE também contribuiu para a construção de um protocolo de acessibilidade a ser disponibilizado à Associação Brasileira de Antropologia. Esse documento, ainda em construção no âmbito do Comitê de Acessibilidade da ABA deve detalhar um conjunto de ações específicas que favoreçam a participação de pessoas com deficiências nos eventos da área, tais como: a veiculação das informações do evento em linguagem de programação específica para pessoas com deficiência visual; as condições de espaço físico e disponibilização de equipamentos para circulação de pessoas com limitações de locomoção; a presença de intérpretes de libras; a elaboração de versões da programação em braile. Acreditamos que através de um conjunto de orientações mais gerais, seja possível garantir condições mínimas de integração de congressistas cegos, surdos,cadeirantes, para os quais já se dispõe de estratégias difundidas de acessibilidade.

Tais orientações, que podem ser sistematizadas a partir da experiência acumulada em diferentes eventos, entretanto estão longe de responde à altura às demandas para promoção de acessibilidade. Por essa razão, é importante refletir sobre os entraves, nem sempre explícitos que se colocam para a efetivação das ações com esse propósito, Três pontos serão enfatizados aqui, no sentido de fomentar o comprometimento com o assunto nas reuniões científicas: 1) o caráter estrutural das demandas; 2) a não especificação das atividades; 3) a independência em relação ao público.

No primeiro aspecto, é importante considerar que o cronograma e o ritmo de organização de um evento nem sempre estão sintonizados com as instâncias locais de promoção da acessibilidade e suas condições específicas de atuação. É fundamental a criação de uma comissão específica que possa iniciar o diálogo com as instâncias responsáveis nas instituições sede. Ao mesmo tempo, é preciso considerar que a atuação dos sujeitos nessa direção depende de uma ação muito bem integrada com todas as demais comissões de trabalho do evento. Demandas muito simples como disponibilizar a intepretação de libras pode se apresentar como um grande desafio. Não se trata apenas de ter um intérprete disponivel fazendo o seu trabalho.

Outra questão geralmente desconsiderada é que as pessoas com os mais diferentes tipos de deficiências e/ou doenças raras se interessarão por quaisquer atividades do evento (não apenas aquelas que pautam esse tema) e precisam ser consideradas como público potencial em todos os espaços. A existência de grupos de trabalho ou mesas que pautam

\footnotetext{
${ }^{7}$ Agradecemos a Escola Estadual de Cegos Cyro Accioly e o Núcleo de Acessibilidade da UFAL que realizaram a impressão da programação em braile. Agradecemos também a edição e transcrição do texto para braile feita por Jean Bernardo da Silva Vieira e Aline Pacheco de Melo Borba.
} 
questões específicas, como tem acontecido nas últimas reuniões de antropologia, muitas vezes precipita a centralização dos recursos de acessibilidade nesses espaços. Obviamente é nesse âmbito que as diferentes demandas de acessibilidade ganham visibilidade e força política. Porém, isso não deve resultar na pressuposição de que é apenas nesses espaços que o público com demandas de acessibilidade estará. Esse ponto está diretamente relacionado com o terceiro aspecto que não pode ser resolvido no âmbito dos protocolos de ação. Quando falamos em promoção da acessibilidade não estamos apenas atendendo a contento demandas específicas de uma pequena parcela de congressistas previamente inscritos no evento.

A armadilha mais comum da qual os organizadores se veem rapidamente enredados ao tentar encaminhar as demandas de acessibilidade e prever recursos para esse fim é haverá mesmo pessoas inscritas com esse tipo de necessidade? Em meio a um cenário de recursos humanos e financeiros escassos, não é incomum que a promoção da acessibilidade seja relegada às últimas posições na lista de prioridades ou demandas emergenciais.

Ao levantar essas questões, queremos mostrar que é fundamental romper com a lógica protocolar de muitas ações direcionadas ao público de pessoas com deficiências ou doenças raras. A questão da acessibilidade não pode ser pensada como uma ação direcionada para um público específico e sim como uma demanda que atinge ao público do evento como um todo. Pessoas funcionalmente habilitadas e/ou perfeitamente saudáveis podem apresentar a qualquer tempo demandas similares. Além disso, os eventos geralmente têm desdobramentos que ultrapassam o espaço/tempo em que são realizados.

Além disso, no que se refere às estratégias de inclusão, o desenvolvimento de atividades para crianças entre 02 e 10 anos ampliou as condições de participação dos congressistas com filhos pequenos. A $1^{\text {a }}$ ABANNINHA, organizada em parceria com o núcleo de Desenvolvimento Infantil da Ufal, proporcionou a criação de um espaço lúdico e seguro para participação das crianças que vieram acompanhando seus pais. As atividades da ABANNINHA aconteceram nas dependências do próprio Unit, em paralelo às atividades acadêmicas dos congressos.

Outro resultado importante a ser destacado foi a abertura de um espaço mais amplo de interlocução entre estudantes de diferentes níveis de formação, necessário para o alcance de uma maior integração entre os cursos de graduação e pós-graduação. Observamos que na maior parte dos eventos de caráter científico, os espaços que têm sido abertos à apresentação das pesquisas dos alunos de graduação reduzem-se ao formato de pôsteres ou painéis, o que de certo modo inviabiliza o debate acerca da pesquisa realizada por esses estudantes. Assim, pensando em promover cada vez mais a participação de alunos de graduação em eventos do porte da V REA/XIV ABANNE, durante os congressos se propôs um espaço para a apresentação de trabalhos de alunos da graduação vinculados ao 
Programa de Iniciação Científica e de pesquisas referentes aos Trabalhos de Conclusão de Curso no formato de comunicação oral. Neste sentido, consideramos que o II Encontro de Iniciação Científica no formato de Comunicações Coordenadas, possibilitou a apresentação e a circulação das pesquisas que vêm sendo desenvolvidas pelos alunos de graduação, viabilizando o exercício de exposição/fala sobre seus estudos, bem como a atuação dos estudantes de pós-graduação como avaliadores e debatedores de pesquisas que têm sido realizadas nas diversas regiões do país.

\section{CONTRIBUIÇÃO DO EVENTO PARA O PÓS-GRADUAÇÃO}

Avaliamos a contribuição da V REA/XIV ABANNE para o desenvolvimento do PósGraduação em dois planos, um mais geral que contempla as regiões Norte e Nordeste e outro mais específico que diz respeito ao aporte do evento para o recém criado Programa de Pós-Graduação em Antropologia Social da Universidade Federal de Alagoas. No primeiro plano, destacamos a ampliação e a consolidação das redes de divulgação e circulação de produções de conhecimento; o estímulo à produção docente e discente no âmbito das regiões Norte e Nordeste e a integração promovida entre os cursos de graduação e de pósgraduação.

A realização do evento, na cidade de Maceió, contribuiu para a consolidação da área da Antropologia num contexto em que se concentram os principais esforços de expansão da disciplina, tanto no que concerne a integração de novos cursos, quanto a ampliação das estratégias de internacionalização. As atividades desenvolvidas nos congressos abriram espaços para o diálogo entre a produção regional e as diversas atividades dos Programas de Pós-Graduação nacionais e internacionais, proporcionando múltiplas trocas de experiências acadêmicas, políticas e institucionais. Tal intercâmbio tem favorecido uma maior divulgação e circulação da produção de conhecimento e possibilitado a construção de redes de trocas entre esses profissionais que compartilham recortes temáticos e paradigmas teóricometodológicos.

Ainda em termos mais amplos é importante destacar a consolidação de um espaço de interlocução entre os alunos de graduação em Ciências Sociais e áreas afins e os alunos do Pós-Graduação em Antropologia. O espaço das Comunicações Coordenadas deu um novo fôlego à iniciativa empreendida pela primeira vez em 2013 na IV REA/XIII ABANNE, em forma de pré-evento. Organizadas por mestres e doutorandos, os grupos temáticos valorizaram uma dinâmica menos verticalizada e mais cooperativa, porém formalizada de discussão desses trabalhos. Nesse sentido, destaca-se a riqueza das trocas estabelecidas entre os estudantes de diferentes níveis de formação bem como a contribuição de diálogos mais aprofundados sobre experiências concretas de pesquisa. Além disso, não podemos deixar de 
destacar o grande aproveitamento por parte dos graduandos do espaço dos Anais do evento para publicação na íntegra de seus trabalhos.

No segundo plano, destacamos a visibilidade da produção acadêmica dos profissionais do estado de Alagoas. A repercussão dos congressos, torna-se um incentivo tanto à produção dos docentes e discentes do recém criado curso de pós-graduação em Antropologia, quanto à reflexão sobre as assimetrias existentes na distribuição de recursos e sobre a desigualdade nos espaços de atuação entre os Programas de Pós-Graduação das diversas regiões do país. Nesses termos, destacamos a importância política da realização dos congressos, visando a concreta integração das produções antropológicas dessas regiões no conjunto da Antropologia Brasileira.

Consideramos que os congressos repercutiram na circulação das produções de conhecimento desses pesquisadores, resultando na consolidação do vínculo com os grupos e núcleos de pesquisa dos Programas de Pós-Graduação em Antropologia, especialmente das regiões Norte e Nordeste. Enfatiza-se a importância desse vínculo, como resultado dos esforços dirigidos à construção de intercâmbios entre profissionais de instituições de diferentes países, visando a expansão e consolidação das redes de cooperação supranacionais e a efetiva internacionalização da Antropologia Brasileira.

No que tange especificamente a contribuição do evento na implantação do curso de Mestrado em Antropologia Social da Ufal, destacamos especialmente a contribuição dos conferencistas para as atividades dos grupos de pesquisa que constituem o PPGAS e a prospecção de possibilidades de intercâmbio e cooperação com grupos consolidados nacional e internacionalmente. Nesse sentido, é importante destacar que desde a elaboração do projeto de mestrado, o grupo de antropólogos da Ufal avaliou as possibilidades de intercâmbio e cooperação como um elemento estratégico da construção do Programa. Os contatos feitos durante a REA/ABANNE foram de grande importância para fortalecer essa dimensão.

Durante o evento, professores dos quatro grupos de pesquisa se reuniram com os conferencistas convidados, com o objetivo de apresentar as pesquisas desenvolvidas no Programa, bem como consultar esses interlocutores sobre a sua disposição em colaborar com essas atividades. Dessas reuniões de trabalho resultaram a intensificação do diálogo com grupos de pesquisa mais consolidados em âmbito nacional e principalmente a ampliação das redes nacionais para três novas parcerias internacionais na América Latina (Colômbia e México) e uma na América do Norte (Canadá). Vemos na publicação desse primeiro número da Revista Mundaú uma das dimensões da concretização dessa colaboração.

Referente à linha de pesquisa Etnicidade, Corpo e Política, destacam-se os resultados promissores em relação à aproximação dos pesquisadores do Mandacaru - Núcleo 
de Pesquisas em Gênero, Saúde e Direitos Humanos com a professora Adriana Piscitelli ${ }^{8}$ da UNICAMP, e de forma mais ampla com o Pagu - Núcleo de Estudos de Gênero daquela instituição. Já o Grupo de Pesquisa em Etnologia Indígena investiu numa maior aproximação com Juan Pedro Viqueira Albán ${ }^{9}$ e com o Centro de Estudos Históricos do Colégio de México, no sentido de expandir o diálogo acerca de estudos que conjugam uma abordagem histórica e antropológica, especialmente sobre populações indígenas. A essas interações, se soma o investimento em uma parceria regional, através de Jane Felipe Beltrão ${ }^{10}$, com o Programa de Pós-Graduação em Antropologia da Universidade Federal do Pará. Além da interface temática a partir da identificação em torno da problemática dos "direitos diferenciados" que é cara a ambos os grupos de pesquisa, há que se destacar um fortalecimento em termos das redes regionais, no que tange a ligação entre Norte e Nordeste.

Os pesquisadores da linha de pesquisa Práticas Culturais, Imagem e Memória também investiram na ampliação das relações internacionais. O destaque aqui é para um vínculo que se estabeleceu não apenas entre professores e grupos de pesquisa, mas também entre "museus antropológicos". A participação de Nuno Porto ${ }^{11}$ do Museum of Anthropology da University of British Columbia, no Canadá, extrapolou a conferência ministrada no evento e se desdobrou em uma atividade de formação no Museu Théo-Brandão de Antropologia e Folclore. A discussão sobre coleções etnográficas e sobre patrimônio cultural é um investimento compartilhado especialmente entre os dois grupos de pesquisa em Antropologia mais antigos da Ufal, o Laboratório de Antropologia Visual em Alagoas (AVAL) e o Laboratório da Cidade e do Contemporâneo (LACC).

Além do interesse manifesto em torno da construção de outras possibilidades de colaboração a partir da prática museológica, o LACC se beneficiou de uma aproximação com

\footnotetext{
${ }^{8}$ Alguns trabalhos da pesquisadora merecem destaque como, por exemplo: Economias sexuais, amor e tráfico de pessoas(2016); Erotics, love and violence: European women's travels in the northeast of Brazil (2015); Trânsitos: brasileiras nos mercados transnacionais do sexo( 2013); Jóias de Família, gênero e parentesco em histórias sobre grupos empresariais brasileiros(2006).

${ }^{9}$ Entre a produção de conhecimento do autor ressaltamos os seguintes trabalhos: ¿Relajados o reprimidos? Diversiones públicas y vida social en la ciudad de México durante el siglo de las luces, México (1987 e 1999) e Encrucijadas chiapanecas. Economía, religión e identidades (2002).

10 No período da realização do evento, a pesquisadora atuava como vice-presidente da ABA, representando o apoio da Associação e contribuindo significativamente ao tema dos congressos. Para além da contribuição da autora à discussão proposta pelo evento, gostaríamos de destacar dentro da sua produção os seguintes trabalhos: Quilombolas, Indígenas \& Violências: segredos, silêncios e conversas sobre crime. (2015); e em parceiria com Assis da Costa Oliveira, o livro Etnodesenvolvimento \& Universidade: formação acadêmica para povos indígenas e comunidades tradicionais(2015).

${ }^{11}$ Entre as publicações do autor, destacamos: Modos de Objectificação da Dominação Colonial - O caso do Museu do Dundo, 1940-1970 (2009); Angola a Preto e Branco - Fotografia e Ciência no Museu do Dundo (1999).
} 
a antropóloga mexicana María Graciela Alcalá Moya ${ }^{12}$, professora da Universidad Nacional Autónoma de México. A mesma desenvolve pesquisas sobre políticas de pesca no México e na América Latina o que veio a contribuir com uma discussão efervescente na realidade alagoana que é a da remoção de comunidades de pescadores na cidade de Maceió. A partir da interlocução com a pesquisadora, foi possível identificar fortes convergências em torno da problemática experimentada pelas comunidades tradicionais no confronto com as políticas de desenvolvimento regional, que possibilitam uma instigante possibilidade comparativa para pesquisadores de ambos os contextos.

Ainda sobre novas possibilidades de cooperação e parceria institucional, destaca-se a interlocução do AVAL com o pesquisador Jairo Tocancipá-Falla ${ }^{13}$, da Universidad del Cauca na Colômbia, cujas pesquisas versam sobre saberes, conflitos e produção de conhecimentos com populações indígenas, na Amazônia e região Andina. Nesse intercâmbio, a aposta esteve nas possibilidades de troca entre pesquisadores, na discussão sobre populações indígenas em contextos de pesquisa marcados por significativas diferenças geopolíticas. Outra aposta do AVAL em parceria com pesquisadores do UNIT, foi a aproximação com a antropóloga Clarice Ehlers Peixoto ${ }^{14}$, cuja experiência na produção audiovisual tem especial destaque no país, visando proporcionar o refinamento dos conhecimentos acerca da metodologia audiovisual nas pesquisas que usam imagens.

Outras contribuições que podem ser elencadas em relação ao desenvolvimento do Programa de Pós-graduação em Antropologia na Ufal é a mobilização do corpo docente para a organização de uma nova revista de antropologia vinculada ao Programa. Nessa direção, foi feito um importante movimento na organização de uma publicação que reunisse as contribuições dos conferencistas para o debate em torno do tema do evento: "Direitos Diferenciados, Conflitos e Produção de Conhecimentos". Essa publicação, a ser apresentada sob forma de número inaugural, impulsionou o trabalho do corpo docente na organização de um canal próprio de divulgação do conhecimento antropológico.

\footnotetext{
12 Para conhecimento de parte da produção da pesquisadora, ver: Políticas pesqueras en México (1946-2000). Contradicciones y aciertos en la planificación de la pesca (2003); Los pescadores de Tecolutla. El tiempo cotidiano y el espacio doméstico en una villa de pescadores (1985). Pescadores en América Latina y el Caribe: Espacio, población, producción e política (2011).

${ }^{13}$ Entre os trabalhos do autor que demostram maior aderência ao tema do congresso, destacamos: "Movimientos Sociales, cultura política y poder regional (2004); "El Trueque: tradición, resistencia y fortalecimiento de la economía indígena en el Cauca"( 2008).

${ }^{14}$ Destacamos aqui os a produção fílmica da autora.: 'Em busca do pequeno paraíso' (1993); Bebela e a Revolução Gaúcha de 1923 (2004); Etienne Samain, de um caminho a outro (2008); Gisele Omindarewa (2009); Itha Grande em outros tempos (2010); Roberto DaMatta e seus carnavais, malandros e heróis (2013); IntraMuros (2015). Dentre sua produção bibliográfica, queremos destacar os livros: Envelhecimento e Imagem: as fronteiras entre Paris e Rio de Janeiro (2000); Antropologia \& Imagem: narrativas diversas e Antropologia \& Imagem: os bastidores do filme etnográfico(2011); Famílias em Imagens (2013). Etnografias Visuais. Análises Contemporâneas (2015).
} 
Deve-se destacar também a visibilidade conferida pelo evento ao processo de seleção da primeira turma do curso de mestrado de Antropologia Social da Ufal. Essa visibilidade deve ser dimensionada em termos de uma projeção regional e nacional, como forma de reconhecimento público para o início das atividades do mais novo curso de formação em pós-graduação da área de antropologia. Ao mesmo tempo, a circulação das informações sobre o evento teve um impacto direto na divulgação do edital de seleção propriamente dito, entre os estudantes interessados em ingressar no curso de mestrado imediatamente através da primeira seleção, que viria a se realizar no mês de agosto, ou nas próximas edições.

Por fim, cabe destacar a capacitação do corpo docente e discente (de graduação) para a organização de reuniões científicas dentro do estado de Alagoas. Através do envolvimento direto com os desafios implicados na realização de uma atividade dessa magnitude, aprendemos o quanto esse tipo de evento, que privilegia trocas de experiências e conhecimentos, ainda é incomum em nosso estado. Nessa direção, a contribuição dos congressos para o sistema de pós-graduação deve ser pensado, em âmbito local, numa perspectiva ainda mais elementar que é a da constituição de uma plateia acadêmica, profissional e/ou politicamente engajada com as populações socialmente vulneráveis no estado de Alagoas.

\section{A PROGRAMAÇÃO DO EVENTO E SEUS PRODUTOS}

As 100 atividades propostas para a V REA/XIV ABANNE foram distribuídas em: 07 Conferências, 14 Mesas Redondas, 11 Fóruns Temáticos, 07 Sessões Extramuros, 08 Minicursos, 39 Grupos de Trabalhos, 12 Comunicações Coordenadas, a I Abaninha e a Mostra Livre de Filmes Etnográficos, Etnografias Sonoras e Fotografias ${ }^{15}$.

Cabe destacar que, em 2015, no período da organização e realização dos congressos, técnicos e docentes da Ufal estavam em greve. Esta situação impactou a realização do evento, desde sua divulgação dentro da Ufal até a participação dos alunos. Nesse mesmo período, outras instituições públicas federais e estaduais do país também estavam em greve, o que era o caso das escolas estaduais no estado de Alagoas. Com a referida greve, que se somou ao período de recesso escolar no UNIT e nas demais universidades privadas de Maceió, a maioria dos alunos residentes no interior do estado tiveram sua participação no evento inviabilizada, devido à ausência de transporte público gratuito.

\footnotetext{
15 Dessas atividades apenas uma não se realizou, em virtude de uma sobreposição de compromissos do proponente de um dos minicursos.
} 
Além das referidas dificuldades, é necessário destacar a demora na liberação dos recursos da CAPES e da FAPEAL que criaram transtornos no processo de financiamento dos proponentes das atividades. Em contrapartida, ao abrir o espaço das Sessões Extramuros (atividades não previstas na proposta inicial, mas que constam na programação final do evento), contamos com a participação de um público que não foi estimado. Referimos-nos aos indígenas, líderes religiosos, pescadores, quilombolas, membros de ONGs e gestores públicos que contribuíram com o evento trazendo demandas específicas locais para serem debatidas junto aos profissionais da antropologia. Para melhor sinalizar tais impactos, na tabela abaixo, apresentamos os dados que mostram o público esperado e o número de participantes no evento.

\section{Quadro 1 - Público do evento}

\begin{tabular}{|c|c|c|}
\hline Público & ESPERADo & EFETIVADO \\
\hline Professores/Pesquisadores & 384 & 339 \\
\hline Professores de Educação Básica & 136 & 36 \\
\hline Alunos de Pós-Graduação & 380 & 393 \\
\hline Alunos de Graduação & 400 & 187 \\
\hline Outros (indígenas, líderes religiosos, & & 47 \\
\hline pescadores, quilombolas, membros de ONGs, & - & 1002 \\
\hline
\end{tabular}

Fonte: listas de presenças assinadas em cada atividade realizada durante o evento.

Com o objetivo de alcançar uma maior divulgação e participação nos congressos, dirigimos nossos esforços para a realização dos seguintes produtos: 1. Caderno de Programação (ISSN: 978-85-7177-886-32); 2. Caderno de Programação em Braile; 3. Videoconferências produzidas pela TV ABA; 4. Mídia com a produção da Mostra-Livre; 5. Publicação eletrônica dos Anais da V Reunião Equatorial de Antropologia e XIV Reunião dos Antropólogos do Norte e Nordeste e 6. Dossiê "Direitos Diferenciados, Conflitos e Produção de Conhecimentos" contendo os textos das Conferências organizados em número especial de Lançamento da Revista Mundaú do Programa de Pós-Graduação em Antropologia da Ufal, na qual inserimos esse relato reflexivo. 


\section{BIBLIOGRAFIA}

AMORIM, Siloé Soares de.Serra das Viúvas. [Filme]. Direção de Siloé Soares de Amorim. Brasil, 2015, $15 \mathrm{~min}$.

ALCALÁ MOYA, María Graciela. Políticas pesqueras en México (1946-2000). Contradicciones y aciertos en la planificación de la pesca nacional México: COLMEX-CICESECOLMICH, 2003.

. Los pescadores de Tecolutla. El tiempo cotidiano y el espacio doméstico en una villa de pescadores. México: Cuadernos de La Casa Chata 119 y Museo Nacional de Culturas Populares,1985.

- Pescadores en América Latina y el Caribe: Espacio, población, producción e política. México: Universidad Nacional Autónoma de México, 2011.

BELTRÃO, Jane Felipe. Quilombolas, Indígenas \& Violências: segredos, silêncios e conversas sobre crime. Revista InSURgência, v. 1, p. 64-81, 2015;

BELTRÃO, Jane Felipe; OLIVEIRA, Assis da Costa (Orgs.). Etnodesenvolvimento \& Universidade: formação acadêmica para povos indígenas e comunidades tradicionais. Belém : Editora da UFPA,. 2015.

PEIXOTO, Clarisse Ehlers. Em busca do pequeno paraíso [Filme]. Direção de Clarisse Ehlers Peixoto, Brasil, 1993, 19 min.

2000.

Envelhecimento e Imagem: as fronteiras entre Paris e Rio de Janeiro. São Paulo: Annablume, $\overline{40 \mathrm{~min} .}$

Bebela e a Revolução Gaúcha de 1923 [Filme]. Direção de Clarisse Ehlers Peixoto, Brasil, 2004, . Gisele Omindarewa [Filme]. Direção de Clarisse Ehlers Peixoto, Brasil, 2009, 65 min.

. Itha Grande em outros tempos[Filme]. Direção de Clarisse Ehlers Peixoto, Brasil, 2010, 40 min

. Antropologia \& Imagem: os bastidores do filme etnográfico. Rio de Janeiro: Garamond, 2011.

PEIXOTO, Clarice Ehlers. IntraMuros [Filme], Direção de Clarisse Ehlers Peixoto, Brasil, 2015, 36 min.

PEIXOTO, Clarice Ehlers; COPQUE, Barbara; LUZ, Gleice Maria Mattos de Vasconcellos; CARVALHO, C. A. de; BRUNO, Fabiana. Etienne Samain: de um caminho a outro [Filme]. Direção de Clarisse Ehlers Peixoto, Brasil, 2008, 35 min.

PEIXOTO, Clarice Ehlers; COPQUE, Barbara; LUZ, Gleice M. Mattos de V. (Orgs.) Famílias em Imagens. Rio de Janeiro: Ed. FGV, 2013.

PEIXOTO, Clarice Ehlers; COPQUE, Barbara (Orgs.). Etnografias Visuais. Análises Contemporâneas. Rio de Janeiro: Garamond, 2015.

PEIXOTO, Clarice Ehlers.; RODRIGUES, Mariana L.; COPQUE, Bárbara.. 'Roberto DaMatta e seus carnavais, malandros e heróis' [Filme]. Direção de Clarisse Ehlers Peixoto, Mariana L. Rodrigues, Bárbara Copque, Brasil, 2013, 40 min. 
PISCITELLI, Adriana G. Economias sexuais, amor e tráfico de pessoas - novas questões conceituais. Cadernos Pagu, v. 1, p. 1-18, 2016.

Erotics, love and violence: European women's travels in the northeast of Brazil. Gender Place and Culture, v. 1, p. 1-14, 2015.

. Trânsitos: brasileiras nos mercados transnacionais do sexo. Rio de Janeiro: EDUERJ/Garamondo/CLAM, v. 1, 2013.

. Jóias de Família, gênero e parentesco em histórias sobre grupos empresariais brasileiros. Rio de Janeiro: Editora UFRJ 2006.

PORTO, Nuno. Modos de Objectificação da Dominação Colonial - 0 caso do Museu do Dundo, 19401970. Lisboa: Fundação Calouste Gulbenkian, 2009.

- Angola a Preto e Branco - Fotografia e Ciência no Museu do Dundo. Coimbra: Museu Antropológico da Universidade de Coimbra, 1999.

TOCANCIPÁ-FALLA, Jairo. Movimientos Sociales, cultura política y poder regional. In: Journal of Latin American Anthropology, v.1,p.1 - $37,2004$.

El Trueque: tradición, resistencia y fortalecimiento de la economía indígena en el Cauca. In: Colombia. Revista De Estudios Sociales Universidad De Los Andes, v.3, p.146 - 161, 2008.

VIQUEIRA, Juan Pedro Albán. ¿Relajados o reprimidos? Diversiones públicas y vida social en la ciudad de México durante el siglo de las luces. México: Fondo de Cultura Económica, 1987.

. Une rébellion indienne au Chiapas, 1712. Paris: L'Harmattan, 1999.

Encrucijadas chiapanecas. Economía, religión e identidades. México:Tusquets Editores/El Colegio de México, 2002. 